\title{
Special issue Anthropocene matters: envisioning sustainability in the Sinosphere
}

\author{
Andrea Riemenschnitter ${ }^{1}$. Jessica $\operatorname{Imbach}^{1}$
}

Received: 4 May 2018/Revised: 6 May 2018/Accepted: 8 May 2018/

Published online: 23 May 2018

(C) Academy for International Communication of Chinese Culture and Springer-Verlag GmbH Germany, part of Springer Nature 2018

As a temporal and analytical framework, the geological epoch of the Anthropocene is currently gaining wide recognition in the humanities. Reaching out beyond its scientific origin (Crutzen and Stoermer 2000), the concept has helped to shift the anthropocentric inclination of our disciplines towards interdisciplinary approaches that are more inclusive in scope, especially with respect to planetary and other-thanhuman agencies and concerns. Numerous books and journal articles testify to what amounts to an "environmental turn" that traverses a variety of academic disciplines, from the natural sciences to seemingly distant fields of inquiry like art history or literary criticism. In this way, the multifarious threats that ecosystems, in their human-nonhuman entanglements, face on a damaged planet attain a cultural presence that will hopefully facilitate public cooperativeness. On a more abstract plane, their labor of working through the methods, theories and narratives of involved disciplines in collaborative intersectional analyses allows scholars in the emergent field of environmental humanities to contribute substantially to a profound epistemological reorientation when responding to the transformations of planetary life and matter in the wake of climate change and other large-scale environmental issues - that are substantial part of the Anthropocene's epochal specificity and, as phenomena with a heavy impact on ecosystems, were suggestively named "hyperobjects" in Timothy Morton's terminology (2013).

Confronting these challenges, environmental humanities focus on the "interface between social and biological systems" (Heise and Carruth 2010, p. 3) in order to identify alternative ways for human beings, under the condition of their being

Andrea Riemenschnitter

andrea.riemenschnitter@aoi.uzh.ch

1 University of Zurich, Zurich, Switzerland 
enmeshed "within the material flows, exchanges, and interactions of substances, habitats, places and environments" (Alaimo 2011, p. 281), to build new imaginaries, formulate new discursive practices, and enable change in their societies' economic and political structures (Oppermann and Iovino 2017, p. 2f). An increasing number of research centers for environmental humanities are devoted to tackling the challenges of the Anthropocene in a joint effort to "veer off the idea of culture and education as "spiritual' abstractions." This could be enacted in explorations of the potential of these resources for recommending sustainable models of community life by "laying bare the production processes and impacts" of those hegemonic texts and narratives that have so far supported our epoch's globalized, unsustainable version of modernity, or even continue to do so (Ibid, p. 3). Hence, interrogating the means and media that helped to produce the Cartesian anthropocentric mindsets is seen as a future-oriented endeavor in support of the social agents and institutions laboring to fend off the risk of a collapse equal only to the "Yucatan meteorite, or... the mysterious forces that, almost exactly a quarter of a billion years ago, suffocated most of the Earth's oceans and killed off an estimated 95 percent of the world's species" (Zalasiewicz 2009, p. 156 f). In terms of practical impact, environmental humanities can deliver a broad variety of incentives for all of us to contribute our share to overcome the "ontological dissociation between the human and the not human realms" (Oppermann and Iovino p. $3 \mathrm{f}$ ) and thereby reach a consensus on the long-needed non-anthropocentric, life-sustaining framework for planetary togetherness that can effectively mitigate inequality, injustice and uncontrollable risks.

At the same time, critics of the environmental humanities' employment of the concept of the Anthropocene bemoan its exploitability by neoliberal capitalism and mainstream politics. We fully agree with the editors of a volume on the material condition and affective textures accompanying the present tumbling of worlds and habitats towards nonlivability that—despite the notion's obvious ambiguities-it is important to join the conversation on the Anthropocene in a world where its ghosts and monsters become ever more tangible, and that this conversation should be conducted without carrying along "the worst uses of the term from green capitalism to technopositivist hubris" (Tsing et al. 2017, p. G 3).

In the field of Asian Studies, scholarship on the region's material, social and cultural transformations due to environmental degradation still needs to catch up with new realities affecting political governance, activism, debates, cultural representations and academic discourses on site. Hence, and for reasons of limited space, our entry into this vibrant field of inquiry can only offer preliminary glimpses into both official and unofficial discourses as well as emergent research topics as developed in China and the Greater Chinese sphere of interest and influence-which for lack of a more suitable concept we address as a conceptual extension of the Sinosphere, originally a geopolitical, shared civilization- and script-focused demarcation (see, i.e., Duara 2015, p. 156 ff; Phillips 2010, p. 149 ff). This special issue is an outcome of the workshop "Humanistic Scholarship in the Anthropocene. Approaching China from a Sustainability Paradigm," organized at the University of Zurich in 2015. Taking Gayatri Spivak's call to "imagine ourselves as planetary subjects rather than global agents" (Spivak 2005, p. 73; quoted in Imbach 2017) as a starting point, the selected papers study voices and representations that bring to the 
fore the negative impact on the regional ecosystem of China's growing economic power as well as possible pathways for change. Our attempts to limn the field of responses is focused on local media and activist voices, works of literature and art, and other more fuzzy cultural reactions to the visible material consequences on site as well as visions for a post-anthropocentric future. For instance, we address cultural representations that in one way or another elaborate on ethical and aesthetic refigurations that critically interrogate the consumer capitalist myths and aim at new identity assemblages that may foster an orientation towards accountability, solidarity, and spiritual and physical wellbeing.

The contributions to this volume contend that technological and corporate driven solutions are not sufficient effectively to address the aggravating environmental problems, and hence ask how communities and individuals grapple with the crisis from a Chinese point of view, and what is at stake in the different approaches taken. Voices addressing the problems and issues of anthropogenic environmental disasters do not only observe the visible violations and abuses at their origin, or interrogate the prevailing sets of knowledge production and moral values that are conducive to the excessive risk-takings of dirty industries, but moreover critically reflect on all domains of modern everyday life from individual lifestyles and religious orientations to economic practice and state-sponsored tools for mitigation. In one way or another, the papers moreover explore the reappearance of other, oftentimes premodern forms of a relationship with the planet's nonhuman organisms that were imagined or spelled out in the past by members of the educated Chinese elite and are currently mobilized and reconfigured to challenge the predominant scheme of radical alienation, objectivation and exploitation of natural resources. As such, this issue engages with a broad spectrum of perspectives on sustainability across the Sinosphere, ranging from official technological solutions and soft power investments in public environmental awareness to unofficial calls for the aesthetic reconstruction of landscapes and new models of ethical human-nonhuman relationships. As humanities scholars working on China we hope to identify and outline ways in which the twenty-first century's prospective leading economy, as a swiftly rising geopolitical force, not only contributes to the global destruction of ecosystems and livelihoods, but also to finding and implementing sustainabilityoriented solutions within and beyond its national boundaries.

Delimiting the emergent field of Asian environmental humanities, Prasenjit Duara's position paper outlines the challenges and opportunities for stakeholders to inaugurate or disseminate new values for a sustainable future with as many surviving ecosystems as possible. While Asia's vulnerable landscapes, vast populations, megacities, and economic growth-oriented politics present a more acute threat to global climate change than the conditions prevailing in other continents, its religions and cultural traditions also provide inspiration for the radical change of ethical imperative and perspective on the constituents of human flourishing that the world needs in order to save the planet, he argues. Among other things, this means that "governments should be oriented to increase not consumption but human capabilities" (Duara, in this volume). Today, the major research questions in the study of climate change and the environment in other disciplines focus on issues of adaptation, mitigation, and the differentiation of 
impact. The role of the humanities in this global project is to contribute their own theoretical outlooks as well as to tell stories, for example from and about grass roots stakeholders, to bring awareness and support to their causes. But the humanities can do more than that by connecting the frequently disaggregated research themes of adaptation, mitigation, refuge, representation and resistance. For example, grass roots movements focused on new concepts of human-nonhuman conviviality and spiritual revitalization - for example in green religious alliances, such as Mahayana Buddhist societies on Taiwan or the Chinese Daoist Association in Mainland China-reveal "new types and scales of alliances as well as emergent values and paradigms" (ibid.), which require new interdisciplinary research methodologies. There is no guarantee that these changes will be sufficiently powerful, or achieved in time to avert the impending catastrophe. However, since historically the humanistic disciplines contributed to the construction of the subjectivities suited to the 'modern' age, they may now very well support the formation of new types of subjectivities "that incorporate natural and planetary consciousness, identity, will, and leadership for a sustainable modernity" (ibid.).

Among specialists in different disciplines, it is not yet clear whether the geological age of the Anthropocene began with the industrial revolution, the discovery of the Americas, or even earlier still. However, there exists a broad scientific consensus that humanity impacts our planet on a global scale and determines, in Duara's words, "the sustainability of the Earth more than any other force." In her paper, Susanne Weigelin-Schwiedrzik offers an overview of the various attempts by international humanities scholars and grass roots organizations to locate incentives in Asian-and especially Chinese-traditions for the creation of environmental awareness, and thus usher in alternative, sustainable forms of interaction between societies and nature. In a next step, she reviews the scientific reception of the notion of the Anthropocene in China proper and a novel of that title by Zhao Defa. She argues, however, that so far none of these environmentalist discourses have brought about the required changes in mindset and behavior. From this the conclusion must be drawn that insights "from the sciences and environmental enthusiasm are not strong enough to convince those longing for wealth and power to change their lifestyle before the catastrophe arrives" (Weigelin-Schwiedrzik, in this volume). The practical solution of green GDP measuring implemented by the government looks more promising, although it does not come without its own particular risks. Whereas "doing things with numbers" has long been an obsession in Chinese politics and still has special persuasive power, fake data have always been a problem and may become even more so in the future. In fact, the dangers of green GDP politics degenerating into a "utopian movement of playing green numbers" (ibid.), or developing into a project of disempowerment, may even pale against the coercive power of data to enforce citizens' (green) behaviors.

The Chinese government's growing interest in exerting soft power by achieving global leadership in climate change politics is discussed in the contribution by Adrian Rauchfleisch and Mike Schäfer. China has been facing domestic pressure to increase its efforts to clean up degraded landscapes and polluted common goods such as water, air, and soil for some time now, but has in recent years continuously 
taken on a more active role in global climate politics as well. The authors identify the Trump government's dismissive attitude towards environmental issues in general and climate change in particular as an important opportunity for China to win international recognition for its active support of sustainable development and thereby gain global political influence. However, China's ability to achieve soft power through climate change politics hinges not only on fulfilling its own environmental goals, but also on its human rights situation, they suggest. And we might add that in the context of the Belt and Road Initiative its foreign investments and development policy are also likely to be closely monitored for their achievements and failures by international environmental stewards (Chan 2018).

One important dimension of "human flourishing" is the biosphere and it is not surprising that Asia's fast-paced urbanization has been accompanied by an increasing demand for green spaces. The pressures of real-estate development and population density on green infrastructures have, according to David Strand, not only resulted in demands for public park conservation and construction, but have also given balconies, drainage systems, roof-tops and abandoned buildings new recreational, alimentary, and spiritual roles. An interesting case is the "green corridor" in Singapore. Long before the government discovered the relinquished rail connection between Singapore and Malaysia as a green space offering high-profile opportunity to increase its environmental prestige, and in 2016 closed it for redevelopment to the dismay of Singapore's environmental organizations, the secondary rain forest and small-scale farm fields surrounding the old train tracks had already been used by residents and railway workers for picnics, the erection of shrines and gardening. Strand argues that such kind of urban green patches-be it gardens, parks, or the rare cases of less manicured landscapes including the remnant minuscule pieces of primary rainforest and the green corridor-are more than simply the "lungs" of the city, but have become increasingly important "entangled spaces," which shape community values and can foster new human and non-human coalitions.

Feminist philosophy and cultural studies were among the first disciplines to address the damage inflicted on human-nonhuman relationships, human societies and the whole ecosystem by neoliberal capitalism and its foundational dualistic worldview. Since then, and by means of strong moral appeals to abolish this globalized system of natural resource raiding, the voices from this particular group of environmental change agents have distinctively shaped the environmental humanities perspective on Anthropocene aesthetics and poetics. Justyna Jaguścik introduces the work of three Mainland Chinese women poets and multimedia performers, and contextualizes a selection of their poems both within feminist environmental and matter-oriented theories as proposed by Bonnie Mann and Stacy Alaimo and traditional Chinese aesthetics. She identifies three main features of their cultural production: "a gendered perspective, socio-ecological concern, and interest in the local aesthetic tradition" (Jaguścik, in this volume). For instance, a traditional cosmological principle like the vital force qi-a kind of universal breath connecting heaven, earth and the 10,000 things of the world (including human beings) - is represented as perverted into the equally ubiquitous and invisible toxicity (du) of contaminated air, soil and water in one of the poets' creative comments on 
environmental degradation. Other poems and art works engage in a similar fashion with the renegotiation of traditional cosmological concepts and shanshui landscape aesthetics to address the (slow) violence and ironies of the booming economy. The topics of these works include the exploitation of landscapes and human life for short term profit and the increased exposure of women and children to unhealthy environments. The author concludes with a list of four responses she sees as characteristic of feminist Chinese Anthropocene subjectivities: grief for lost landscapes, nostalgia for ancient cosmological thought, anxiety on account of toxic environments, and solidarity with the suffering of the lower rungs of society, future generations, and nonhuman organisms.

Traditional shanshui art has not only made it into the unofficial, independent art production discussed by Jaguścik, but is also mobilized by the government's propaganda machine to convey the core concerns of its environmental modernization policy to the population by means of landscape appreciation in a distinctly local key, argues Andrea Riemenschnitter. Doing field work in Shanghai, she documented the 2015 New Year's China Dream posters, among which Feng Zikai's 1930s landscape cartoons stood out both in number of works displayed and elaboration of design. If a dream of healthy, beautiful landscapes is at stake in Xi Jinping's utopian narrative, then the choice of these particular works with their inherited surplus symbolic inscriptions requires interpretation. Since Chinese dream narratives contain ambiguous root metaphors that are inherited from the ancient canon-and part of these same encourage to negate or even entirely renounce the mundane world - the advertisements afford fuzzy readings, to say the least. Moreover, his landscapes carry on with the ancient tradition of hiding moral appeals in shanshui landscape art. There is one group of concerned citizens with whom a critical, futureoriented dialogue can be conducted, though. An anxiety-ridden type of multi-media landscape art-not exclusively cultivated by the feminist creative scene as described by Jaguścik, but also produced by internationally successful male artists such as Cai Guoqiang and Ji Yunfei, or staged by young experimental local artists such as the cooperative from Hangzhou who named themselves "Open Matter Research Institute" (Riemenschnitter, in this volume)_-merges modern Western and ancient local aesthetic paradigms to address contemporary worries. These, at times quite apocalyptic, images of the nation's environmental wounds call for emergency rescue: destitute post-industrial landscapes, decaying workers' bodies, sick children, lethally damaged nonhuman life. The propaganda machine's participation in the cultural revitalization of traditional cosmological principles inherent in the nation's prestigious shanshui art, and the fact that so many unsettling ecocritical works of art were displayed in a state-sponsored exhibition, arguably hint at a deliberative dialogue between official and unofficial discursive spheres on what values and paradigms should be implemented to best assist the country's struggles for environmental rehabilitation, Riemenschnitter concludes.

Apparently, in the realm of the humanities and cultural production the bulk of answers to the question of who or what has the power to bring about the broadly desired, resolute turn towards sustainability leads us back to those forms of weak environmentalism favored by Duara. A residual belief-or shall we say hope?-in redemptive aesthetic education through poetry, performance, and the visual arts 
grounds the materials studied by the two following papers, too, which explicitly engage with Duara's notion of dialogic transcendence. Both contributions comb through the cultural resources for a coming environmental ethics by studying historical ethnographic evidence about human relationships with other species as enacted in ritual contexts, or analyzing stories that highlight individual human engagement with endangered species as told in modern and contemporary literary or filmic fiction. Annu Jalais revisits ancient Chinese tiger lore and ritual tiger symbolism before and after the advent of the Buddhist command of universal compassion with all forms of life, arguing that the earliest ritual and functional meanings of tigers somehow determined the later Buddhist recodings. Whereas in India strong and dangerous animals such as elephants and tigers were venerated as the terrestrian kin or embodiments of ultimately benign divinities even before Buddhism transcended these ancient cults, early Chinese cosmologies legitimized the aristocracy's killing of these same animals in hunting events and ritual sacrifice. No matter whether they were depicted as "agents between the living and the dead" (Jalais, in this volume) on ritual vessels, or their skulls and bones were made use of in rain-making rituals, there seems to have been very little, if any, ethical imperative to protect the lives of tigers or other nonhuman species beyond their functional value in serving human communities as either food, tools, or ritual offerings. Contrary to the Indian traditions, where concepts of devotion and compassion towards non-human life and indeed even "inanimate objects constitutive of nature" (ibid.) have played a big role in shaping an environmental ethics avant la lettre, the historical sources from the Sinosphere bespeak the systematic, large-scale extermination of dangerous animals and their habitat from early on. This makes it difficult to argue for a distinctly (premodern) Chinese approach towards dialogic transcendence suitable to fostering new forms of sustainable human-nonhuman bonds that are derived from, but no longer exclusively tied to local religious traditions - maybe with the exception of the activism and environmental stewardship of the rejuvenated Daoist and Buddhist associations studied by Duara (2015).

Haiyan Lee continues this thread of reflection, but contrary to Jalais demarcates a possible Chinese solution to the religious transcendence conundrum. Before turning her attention towards two novels and a movie, her paper merges various theoretical components to outline a topical variety of environmental ethics for the Sinosphere. She argues that the holistic communitarianism of Aldo Leopold's land ethic and the deontological argument of animal rights activists-who find themselves ridiculed by critics as pug-lovers for their rigid verdict against any violation of any creature's supposed right to live-cannot easily be reconciled. However, a post-Confucian universalistic, or first order principle in conjunction with exemplary fictional narratives of what she calls an "ecology of the particular" (Lee, in this volume) might help. Browsing the recent, multifarious efforts of moral philosophers to reckon with the challenges of the experimental sciences of consciousness and morality, she finds valuable support of her argument in an ethical recoding of the originally psychological concept of affordance. In the past, moral philosophy has mostly encouraged people to "adopt a third-person perspective that permits selfdistancing and self-critique," she contends. By doing this, it "grossly underappreciated the 'thickness' of our ethical life, i.e., its emotional and interactive 
dimensions in the first- and second-person settings, the realm of dialogues and contingencies" (ibid.). The unexpected bonds between a fictional French resistance fighter and labor camp survivor in Africa and the continent's ferociously hunted elephants, between a Chinese photo-journalist and a newly discovered monkey species sold as a medical alcoholic concoction in Western Hubei, and between a couple of involuntary surrogate parents and an animated baby monster meant to end up on the gourmet dining table of an imaginary China lead her to fuse "thick and thin" environmental justice perspectives in universal moral and affective intensity: parental love and care. In order to make the post-Confucian version of this ethical claim work, both the originally functionalist approach towards the non-human in ancient Confucian moral thought and the corrosive parts of our love, which frequently lead us to "destroying the very thing that we love or blinding us to the externalities of our appetites" (ibid.) must be overcome. The three groups of literary and filmic protagonists discussed by Lee indeed achieve this much through their love and care for other species, be it elephants, monkeys, or monsters. By dwelling on the particular, literature and the arts can incubate a new ecological imagination or romance of the species, that, in the eloquent wording of her argument, "is neither naively anthropocentric nor radically posthuman," but "bores past our boundaries and defenses" to send up sparks for a "prairie fire from which a phoenix can rise up."

\section{References}

Alaimo, Stacy. 2011. New Materialisms, Old Humanisms, or, Following the Submersible. NORA—Nordic Journal of Feminist and Gender Research 19 (4): 280-284.

Chan, Wai-shin. 2018. How China Can Green Its Belt and Road Projects. South China Morning Post (Jan. 21). http://www.scmp.com/comment/insight-opinion/article/2129647/how-belt-and-road-initiativecan-be-chinas-path-green.

Crutzen, Paul, and Eugene F. Stoermer. 2000. The 'Anthropocene'. IGB Global Change Newsletter 41 (May): 17-18.

Duara, Prasenjit. 2015. The Crisis of Global Modernity: Asian Traditions and a Sustainable Future. Cambridge: Cambridge University Press.

Heise, Ursula K., and Allison Carruth. 2010. Introduction to Focus: Environmental Humanities. American Book Review 32 (1): 3.

Imbach, Jessica. 2017. Pathways to Sustainability. http://www.asienundeuropa.uzh.ch/de/aboutus/ bulletin/2016/pathways.html.

Morton, Timothy. 2013. Hyperobjects: Philosophy and Ecology after the End of the World. Minneapolis: University of Minnesota Press.

Oppermann, Serpil, and Serenella Iovino. 2017. Introduction. In Environmental Humanities: Voices from the Anthropocene. Rowman and Littlefield International-Intersections, eds. by S. Oppermann and S. Iovino, 1-21. London: Rowman and Littlefield International.

Phillips, Andrew. 2010. War, Religion and Empire: The Transformation of International Orders. Cambridge: Cambridge University Press.

Spivak, Gayatri Chakravorty. 2005. Death of a Discipline. New York: Columbia University Press.

Tsing, Anna Lowenhaupt, Nils Bubandt, Elaine Gan, and Heather Anne Swanson (eds.). 2017. Arts of Living on a Damaged Planet: Ghosts and Monsters of the Anthropocene. Minneapolis: University Of Minnesota Press.

Zalasiewicz, J. 2009. The Earth After Us: What Legacy Will Humans Leave in the Rocks?. Oxford: Oxford University Press. 